\title{
Historical changes in the phenology of British Odonata are related to climate $^{1}$
}

\author{
Christopher Hassall, David J. Thompson, Graham C. French and lan F. Harvey
}

\begin{abstract}
Responses of biota to climate change take a number of forms including distributional shifts, behavioural changes and life history changes. This study examined an extensive set of biological records to investigate changes in the timing of life history transitions (specifically emergence) in British Odonata between 1960 and 2004. The results show that there has been a significant, consistent advance in phenology in the taxon as a whole over the period of warming that is mediated by life history traits. British odonates without an egg diapause significantly advanced the leading edge (first quartile date) of the flight period by a mean of 2.73 days per decade \pm 0.055 (s.e.m., $n=19$ ) or $5.82 \pm 1.15$ (s.e.m., $n=19$ ) per degree rise in temperature. Species exhibiting a diapause in the egg stage did not respond significantly to increases in UK temperatures. This study represents the first review of changes in odonate phenology in relation to climate change and shows that responses to global warming are mediated by life-history traits. The results suggest that the damped temperature oscillations experienced by aquatic organisms compared to terrestrial organisms are sufficient to evoke phenological responses similar to those of purely terrestrial taxa.
\end{abstract}

Key words: climate change; global warming; Odonata; temperature; phenology; biological records; population dynamics; flight period; life-history; diapause.

\section{Introduction}

A trend in environmental warming is now undeniable (Karl \& Trenberth 2003). Whether anthropogenic or natural, the effects on a wide range of global flora and fauna are significant and startling (Hughes 2000; Parmesan \& Yohe 2003; Root et al. 2003). Physiological limits for temperature tolerance place restrictions on the persistence of organisms in the face of consistent changing temperature.

Coope (1995) has highlighted three potential responses to persistent climate change: (i) the species can become extinct, (ii) the species can adapt in situ, (iii) the species can migrate to areas with a more tolerable climate. However, flexibility inherent in an organism's life cycle may buffer against the impacts of climate change, thus altering the threshold at which the organism must resort to one of those responses.

In order to cope with seasonal fluctuations in climate, complex life histories have evolved in insects which permit maximum exploitation of warmer seasons while cooler seasons are survived by more resistant forms (Butterfield \& Coulson 1997). The mechanism for seasonal regulation most commonly involves the use of cues such as environmental temperature and photoperiod to determine when to undergo life history transitions. The issue of photoperiod has received attention in a variety of taxa (Butterfield \& Coulson 1997; Gotthard et al. 2000; Johansson \& Rowe 1999; Laurila et al. 2001) and there has been much debate over possible mechanisms for time measurement (Vaz Nunes \& Saunders 1999). There is evidence that critical photoperiods are (Fleming \& Tatchell 1995)changing at the same latitude over time as environmental warming increases amenable growth season (Harada et al. 2005).

With changes in mean environmental temperature over the past century, it seems reasonable to suppose that there will be concurrent changes in the timing of life history transitions. Such changes in phenology have been documented using biological records in a variety of British animals, including Lepidoptera (Ellis et al. 1997; Sparks \& Yates 1997), Homoptera (Fleming \& Tatchell 1995) and birds (Crick et al. 1997).

The Odonata are an ancient order, with all active stages of the life cycle being voracious carnivores. Distributional responses of some Odonata to environmental warming have been noted in some anecdotal

\footnotetext{
${ }^{1}$ Version of record can be viewed at the publisher and should be cited as: Hassall, C., Thompson, D. J., French, G. C. \& Harvey, I. F. 2007. Historical changes in the phenology of British Odonata are related to climate. Global Change Biology, 13, 933-941.
} 
studies (Aoki 1997; Bonsel 1999) and recently Hickling et al. (2005) produced a far more conclusive review of the British species. This study showed that there was a trend towards a northward shift in those range margins that occurred in Britain.

The phenological response of Odonata to changing environmental temperature has not been investigated. This study seeks to examine an extensive collection of biological records in an attempt to discern patterns in flight period for British Odonata over the recent period of warming. The flexibility in the odonate life cycle that permits variation in phenology is due to periods of diapause which, depending upon species, can exist in the egg, larva and adult stages. Previous studies have shown patterns between purely terrestrial insect taxa and changes in ambient temperature (e.g. Fleming \& Tatchell 1995; Sparks \& Yates 1997). By contrast, this study investigates the impact of changing environmental temperature on the phenology of a taxon that has a sensitive period during an aquatic life history stage.

\section{Materials and methods}

\section{(a) The BDS database}

The British Dragonfly Society (BDS) maintains a database of sightings of Odonata from between 1807 and the present. At the time that the database was first analysed ( $28^{\text {th }}$ November 2005$)$, it contained 448,547 records. These records included sightings of individuals (as larvae, adults and exuviae) as well as separate records for selected behaviours (emerging, copulating and ovipositing). However, only records of sightings of adults and exuviae in Britain between 1960 and 2004 were included, since this period represents an anomalous period of warming (Jones \& Mann 2004) and increased recorder effort. Records were also excluded if they were deemed to be duplicates or if they did not have a precise date. This reduced the number of records to 268,772 . Only records recorded between the latitudes of 50 and $52^{\circ} \mathrm{N}$ were included to control for latitudinal variation in flight periods.

Only established, non-migratory British species were selected. Aeshna mixta, although formerly migratory, is now considered a British species. Erythromma viridulum is still classified as a migrant, even though it has bred consistently for the past 4 years, and would be of no use in this study due to its relatively short history in the database. Similarly, the Sympetrum spp. that migrate into Britain in waves before becoming extinct ( $S$. fonscolombii and S. flaveolum) were excluded from the analysis. S. nigrescens was excluded on the basis that it most likely constitutes a melanic form of $S$. striolatum. This selection process left 37 species (see Table 1A).

The annual mean of the Central England Temperature (CET) index was used as a general indicator of British temperatures and was obtained from the Met Office's Hadley Centre. CET has been found to correlate with other regional temperatures and has been used in previous analyses of phenology (Sparks \& Carey 1995; Sparks \& Yates 1997). The annual mean CET between 1960 and 2004 was significantly correlated with spring (March, April and May; $r=0.693, p<0.001$ ) and summer (June, July and August; $r=0.701, p<0.001$ ) mean temperatures and so was used as an indicator of general temperature change over the period.

\section{(b) Analysis}

For each species the records were divided into time periods. This was done in a species-specific way to maximise the resolution in each case. The longest time period was a decade, with the rarest species being grouped into 1960-1969, 1970-1979, 1980-1989, 1990-1999 and 2000-2004 when there were between 30 and 499 records in each period. Periods with fewer than 30 records were excluded. Where there were between 500 and 999 records in a decade, those records were divided into two groups for the first and second half of that decade. Where there were between 1,000 and 4999 records in a decade, those records were divided into 3-year blocks (e.g. 1980-2, 1983-5, 1986-8 etc). In some cases decades exceeded 5,000 records and these were divided into 2-year blocks (e.g. 1980-1, 1982-3, 1984-5 etc). A conservative rule was required because records were not evenly distributed over the years and so care had to be taken to ensure that sufficient records were present in each period.

Species were excluded if they could not be split into 5 or more time periods to maintain the accuracy of the estimated slopes. This led to the omission of Aeshna caerulea, Aeshna isosceles, Coenagrion hastulatum, 
Coenagrion pulchellum, Gomphus vulgatissimus, Ischnura pumilio, Lestes dryas, Leucorrhinia dubia, Libellula fulva and Somatchlora arctica.

The date of each record was then converted into a Julian date. The first quartile (Q1), median (Q2) and third quartile (Q3) were calculated from the distribution of Julian dates for each time period. Due to small sample sizes (5-12 points) non-parametric regression techniques were used. Kendall's robust line-fit method (Sokal \& Rohlf 1995) produced estimates of the slope of the line describing the relationship between date and temperature and each of the 3 flight date statistics. A p-value for each of the lines was obtained using Kendall's rank correlation. All 6 sets of slopes were checked for normality (Anderson-Darling test) and homoscedasticity before being entered into a GLM with taxonomic classification (Anisoptera/Zygoptera), presence/absence of egg diapause (using information in Merritt et al. 1996; see Table 1) and classification as either "spring" or "summer" species (according to the definitions in Corbet et al. 1960).

\section{Results}

\section{(a) Recorder effort}

The number of records in the BDS database is biased temporally, with vastly more records in later periods. When the Q1, Q2 and Q3 statistics for each of the species-specific time periods were analysed against the number of records for the respective periods, there were non-significant relationships between the number of records and Q2 $(r=-0.102, p=0.114)$ and Q3 $(r=-0.043, p=0.507)$ flight dates. There was a significant relationship between the number of records and the $Q 1$ flight date $(r=-0.135, p=0.036)$, but this explained very little of the variance $\left(r^{2}=1.4 \%\right)$ and can therefore be considered unimportant.

\section{(b) Changes in phenology}

There were no significant shifts in phenology that persisted after the reduction of the $\alpha$-value resulting from the Bonferroni correction. However, the samples of $T$-values for the Q1 flight date against both mean CET and date were found to be significantly different from zero using a 1-sample, 2-tailed $t$-test against a test mean of zero (Table 2). Neither median nor Q3 flight statistics advanced significantly in the taxon as a whole with temperature or date.

\section{(c) Traits affecting response}

Taxonomy, egg diapause and spring/summer classification did not have a significant effect on samples of $T$ values apart from the "Q1 vs. year" sample, where species not exhibiting an egg diapause showed significantly greater advances in phenology (Table 3). $T$-values for Q1 vs. both year and mean CET were significantly different between those species exhibiting an egg diapause and those not exhibiting egg diapause (2-sample $t$-test, Q1 vs. year: $t=-2.67, p=0.019$; Q1 vs. mean CET: $t=-2.98, p=0.008)$. $t$-values for species exhibiting an egg diapause were not significantly different from zero but $t$-values for species without an egg diapause were significantly below zero (Table 4 and Figure 1).

\section{Discussion}

As a taxon, British Odonata have significantly advanced their phenology chronologically (on average by around 2 days per decade (Table 1)) and with respect to temperature (on average by around 4.5 days per $1^{\circ} \mathrm{C}$ increase (Table 1A)) over a 45 year period (1960-2004). This shift represents an extension to the preceding edge of the flight period (first quartile flight date) as opposed to a shift of the flight period as a whole. This is the first phenology study of a taxon that is restricted to freshwater bodies to breed and concurs with the findings of studies on terrestrial British invertebrates (Fleming \& Tatchell 1995; Sparks \& Yates 1997).

In addition to being biased temporally, there is no doubt a bias towards the latter stages of the adult lifespan. During the prereproductive period, odonates possess a negative taxis towards reflective surfaces, causing them to disperse varying distances from their natal water body (Corbet 1999). This is reversed to cause an aggregation at water bodies at the start of the reproductive period. Many of the adults sighted will have been more mature individuals at water bodies where adults are at their highest concentrations and, hence, most noticeable. The length of the adult period varies greatly between species. Corbet's (1999) analysis suggested mean adult (reproductive) longevities of between 6.7-37.7 (median=11.5) days for Anisoptera and 3.8-23.3 (median=7.6) days for Zygoptera. This will introduce a small, unavoidable error into the 
calculations. The absence of difference in phenological response between Anisoptera and Zygoptera suggests that varying longevities may not have an effect on the results.

Another factor that may influence results is the varying size of water body in which the different species live. The size of the water body affects the buffering of ambient temperature fluctuations and, therefore, the perception of temperature by aquatic organisms. However, odonates are known to seek out warmer microclimates within water bodies (e.g. Aeshna caerulea, Sternberg 1997), such as riparian vegetation, where such buffering is less effective. The data are not available to study this factor.

\section{Phenology of the Flight Period}

The absence of a shift in the Q3 flight date is harder to explain. Having concluded that most species are advancing in phenology, it would be sensible to predict that the end to the flight season should either (i) advance in a similar way or (ii) regress to mirror the advance of Q1 about the mean flight date.

In support of the former prediction, daily survivorship is constant throughout adult life in many species (e.g. Coenagrion puella; Banks \& Thompson 1985), with some studies showing a decline at the beginning of the reproductive period (Enallagma hageni; Fincke 1982). Therefore, if all individuals share the same cue for seasonal regulation, they should all emerge, live and die at earlier points through the year according to a type II survivorship curve. This pattern appears to be exhibited by Pyrrhosoma nymphula, which shows similar advances in Q1, median and Q3 flight dates (Table 1).

The latter hypothesis is based on the assumption that insects die or become less active in winter due to abiotic factors such as falling ambient temperatures. If global warming is alleviating the temperature stress at the end of the flight season then it seems reasonable to expect that there will be more individuals on the wing at a later date (especially in those species with asynchronous emergence periods). Erythromma najas seems to follow this pattern, with shifts of similar magnitude but in opposite directions in the Q1 and Q3 flight dates and little change in the median (Table 1).

The fact that neither of these patterns is seen as a general pattern in the taxon as a whole suggests that (i) neither hypothesis is correct and there are other factors governing the species-specific response of the latter part of the flight period, or (ii) that both factors are working antagonistically.

\section{Phenology and life-histories}

As previously noted, Odonata possess a number of life history traits which allow regulation of the life cycle in response to environmental conditions. In the case of a diapause in the egg stage, eggs, once laid in summer or autumn, enter developmental stasis where they remain over winter until warmer spring temperatures (or an increase in water levels, in some cases) trigger a continuation of development. The larvae then develop through the spring, emerging asynchronously in summer. Species which do not possess a diapause in the egg stage overwinter as late-instar larvae and use warming temperatures and photoperiod in spring as a cue for emergence. Thus, as this study has shown, species without an egg diapause should have flight periods which are more sensitive to increasing temperatures than species that do possess an egg diapause.

\section{Conclusions}

The Odonata are a warm-adapted taxon (Pritchard \& Leggott 1987) which will certainly favour their chances of surviving climate change. However, a reliance on bodies of freshwater, which are predicted to undergo marked change under current climate change models (Dawson et al. 2003), makes their fate less certain. Patterns seen here in Odonata are likely to be seen in other insects with aquatic stages to their life cycles. As a greater portion of the year becomes suitable for warm-adapted taxa such as Odonata, there is an increased risk of successful colonisation and persistence by disease vectors, which appear to be shifting distributions as temperatures increase (Patz \& Olson 2006).

An ability to exploit temperate zones through the use of complex life histories while retaining thermal adaptations to warmer climates makes this taxon potentially one of the more resilient groups of animals. There is evidence that Odonata are able to shift geographical ranges (Hickling et al. 2005), undergo 
evolutionary change to facilitate dispersal (Taylor \& Merriam 1995), change responses to cues to seasonal regulation (Johansson 2003) and, in the present study, take advantage of climatic warming to expand their flight period through changes in phenology that are governed by life-history traits. This response occurs in the same way as that of animals with a purely terrestrial life cycle, suggesting that aquatic and terrestrial life history stages have a similar sensitivity to environmental warming despite fluctuations being dampened in aquatic environments.

\section{Acknowledgements}

The authors thank the British Dragonfly Society for access to their historical database, the many recorders who contributed to the database and the Hadley Centre for providing climate data. $\mathrm{CH}$ was supported by a NERC Studentship.

\section{References}

Aoki, T (1997) Northward expansion of Ictinogomphus pertinax (Selys) in eastern Shikoku and western Kinki districts, Japan (Anisoptera: Gomphidae). Odonatologica, 26, 121-133.

Banks, MJ, Thompson, DJ (1985) Lifetime mating success in the damselfly Coenagrion puella. Animal Behaviour, 33, 1175-1183.

Bonsel, A (1999) Das Kleine Granatauge (Erythromma viridulum Charp. 1840) in Mecklenburg Vorpommern. Naturschutzarbeit in Mecklenburg-Vorpommern, 42, 48-56.

Butterfield, JEL, Coulson, JC (1997) Terrestrial invertebrates and climate change: Physiological and lifecycle adaptations. In: Past and Future Rapid Environmental Changes: The Spatial and Evolutionary Responses of Terrestrial Biota (ed. B. Huntley, W. Cramer, A. V. Morgan, H. C. Prentice, J. R. M. Allen), pp. 401-412. Springer, Berlin.

Coope, GR (1995) Insect Faunas in Ice Age Environments: Why So Little Extinction? In: Extinction Rates (ed. J. H. Lawton, R. M. May), pp. 55-74. Oxford University Press, New York.

Corbet, PS (1999) Dragonflies: Behaviour and Ecology of Odonata. Harley, Colchester, 829 pp.

Corbet, PS, Longfield, C, Moore, NW (1960) Dragonflies. Collins, London, 260 pp.

Crick, HQP, Dudley, C, Glue, DE, Thomson, DL (1997) UK birds are laying eggs earlier. Nature, 388, 526.

Dawson, TP, Berry, PM, Kampa, E (2003) Climate change impacts on freshwater wetland habitats. Journal for Nature Conservation, 11, 25-30.

Ellis, WN, Donner, JH, Kuchlein, JH (1997) Recent shifts in phenology of microlepidoptera, related to climatic change (Lepidoptera). Entomologische Berichten, 57, 66-72.

Fincke, OM (1982) Lifetime mating success in a natural population of the damselfly, Enallagma hageni (Walsh) (Odonata: Coenagrionidae). Behavioural Ecology and Sociobiology, 10, 293-302.

Fleming, RA, Tatchell, GM (1995) Shifts in the flight season of British aphids: a response to climate warming? In: Insects in a Changing Environment (ed. R. Harrington, N. E. Stork), pp. 505-508. Academic Press, London.

Gotthard, K, Nylin, S, Wiklund, C (2000) Individual state controls temperature dependence in a butterfly (Lasiommata maera). Proceedings of the Royal Society - Biological Sciences (Series B), 267, 589593.

Harada, T, Nitta, S, Ito, K (2005) Photoperiodism changes according to global warming in wing-form determination and diapause induction of a water strider, Aquarius paludum (Heteroptera: Gerridae). Applied Entomology and Zoology, 40, 461-466. 
Hickling, R, Roy, DB, Hill, JK, Thomas, CD (2005) A northward shift of range margins in British Odonata. Global Change Biology, 11, 502-506.

Hughes, L (2000) Biological consequences of global warming: Is the signal already apparent? Trends in Ecology and Evolution, 15, 56-61.

Johansson, F (2003) Latitudinal shifts in body size of Enallagma cyathigerum (Odonata). Journal of Biogeography, 30, 29-34.

Johansson, F, Rowe, L (1999) Life history and behavioral responses to time constraints in a damselfly. Ecology, 80, 1242-1252.

Jones, PD, Mann, ME (2004) Climate over past millennia. Reviews of Geophysics, 42, 1-42.

Karl, TR, Trenberth, KE (2003) Modern global climate change. Science, 302, 1719-1723.

Laurila, A, Pakkasmaa, S, Merilä, J (2001) Influence of seasonal time constraints on growth and development of common frog tadpoles: A photoperiod experiment. Oikos, 95, 451-460.

Merritt, R, Moore, NW, Eversham, BC (1996) Atlas of the Dragonflies of Britain and Ireland. HMSO, London, pp.

Parmesan, C, Yohe, G (2003) A globally coherent fingerprint of climate change impacts across natural systems. Nature, 421, 37-42.

Patz, JA, Olson, SH (2006) Malaria risk and temperature: Influences from global climate change and local land use practises. Proceedings of the National Academy of Sciences of the United States of America, 103, 5635-5636.

Pritchard, G, Leggott, M (1987) Temperature, incubation rates and the origins of dragonflies. Advances in Odonatology, 3, 121-126.

Root, TL, Price, JT, Hall, KR, Schneider, SH, Rosenzweig, C, Pounds, JA (2003) Fingerprints of global warming on wild animals and plants. Nature, 421, 57-60.

Sokal, RR, Rohlf, FJ (1995) Biometry. W.H. Freeman and Co., New York, pp.

Sparks, TH, Carey, PD (1995) The responses of species to climate over two centuries: An analysis of the Marsham phenological record, 1736-1947. Journal of Ecology, 83, 321-329.

Sparks, TH, Yates, TJ (1997) The effect of spring temperature on the appearance dates of British butterflies 1883-1993. Ecography, 20, 368-374.

Sternberg, K (1997) Adaptation of Aeshna caerulea (Strom) to the severe climate of its environment (Anisoptera: Aeshnidae). Odonatologica, 26, 439-449.

Taylor, PD, Merriam, G (1995) Wing morphology of a forest damselfly is related to landscape structure. Oikos, 73, 43-48.

Vaz Nunes, M, Saunders, DS (1999) Photoperiodic time measurement in insects: A review of clock models. Journal of Biological Rhythms, 14, 84-104. 


\section{Tables}

Table 1 - Slopes of relationships between year and mean CET and 3 flight period statistics (all figures are Kendall's $T$ ). Although some relationships were significant at $\alpha=0.05$, a Bonferroni correction for 162 tests reduced $\alpha$ to 0.0003 and resulted in all results being non-significant.

\begin{tabular}{|c|c|c|c|c|c|c|}
\hline & \multicolumn{3}{|c|}{ Year (days per year) } & \multicolumn{3}{|c|}{$\begin{array}{l}\text { Mean CET (days per } 1^{\circ} \mathrm{C} \\
\text { increase in temperature) }\end{array}$} \\
\hline & Q1 & Q2 & Q3 & Q1 & Q2 & Q3 \\
\hline Aeshna cyanea* & 0 & -0.0565 & -0.0571 & 0 & 0.849 & 0.707 \\
\hline Aeshna grandis* & -0.299 & -0.3636 & -0.3515 & -6.82 & -7.70 & -7.97 \\
\hline Aeshna juncea* & 0.0192 & 0.556 & 0.439 & 1.95 & 10.09 & 6.86 \\
\hline Aeshna mixta* & -0.337 & -0.322 & -0.282 & -6.19 & -4.90 & -5.84 \\
\hline Anax imperator & -0.500 & -0.167 & -0.239 & -7.14 & -1.68 & -3.57 \\
\hline Brachytron pratense & -0.500 & -0.250 & -0.222 & -10.6 & -3.53 & -1.98 \\
\hline Calopteryx splendens & -0.0868 & 0.214 & 0.410 & -3.90 & 3.62 & 7.54 \\
\hline Calopteryx virgo & 0.000 & 13.9 & +21.4 & 0.000 & 0.397 & 0.644 \\
\hline Ceriagrion tenellum & -0.0580 & 0.00781 & 0.143 & -1.71 & 1.80 & 5.72 \\
\hline Coenagrion mercuriale & -0.306 & -0.909 & -1.182 & -7.73 & -25.00 & -31.2 \\
\hline Coenagrion puella & -0.344 & -0.391 & -0.0844 & -11.1 & -8.39 & -3.62 \\
\hline Cordulegaster boltonii & 0.0263 & 0.131 & 0.667 & 2.89 & 3.66 & 8.09 \\
\hline Cordulia aenea & -0.222 & -0.6346 & -0.609 & -7.06 & -11.5 & -17.2 \\
\hline Enallagma cyathigerum & -0.401 & -0.117 & -0.0410 & -4.42 & 0.000 & 0.309 \\
\hline Erythromma najas & -0.283 & -0.122 & 0.249 & -6.42 & -0.782 & 10.7 \\
\hline Ischnura elegans & -0.333 & -0.216 & 0.000 & -4.29 & -3.30 & 0.000 \\
\hline Lestes sponsa* & 0.128 & 0.111 & 0.115 & 1.35 & 2.95 & 4.96 \\
\hline Libellula depressa & -0.579 & -0.482 & -0.494 & -12.4 & -6.85 & -9.20 \\
\hline Libellula quadrimaculata & -0.445 & -0.492 & -0.312 & -9.60 & -6.16 & -3.61 \\
\hline Orthetrum cancellatum & -0.1345 & -0.0801 & 0.0288 & -1.13 & -0.955 & 1.54 \\
\hline Orthetrum coerulescens & -0.444 & -0.166 & 0.0656 & -9.32 & -0.974 & 1.16 \\
\hline Platycnemis pennipes & 0.0385 & 0.0769 & 0.308 & 0.000 & 1.77 & 12.36 \\
\hline Pyrrhosoma nymphula & -0.750 & -0.786 & -0.797 & -16.1 & -16.2 & -15.6 \\
\hline Somatochlora metallica & 0.133 & 0.526 & 0.0548 & -0.561 & 7.37 & -0.162 \\
\hline Sympetrum danae* & -0.0481 & 0.273 & 0.123 & 1.58 & 6.58 & 0.277 \\
\hline Sympetrum sanguineum* & 0.400 & 0.273 & 0.000 & 3.50 & 0.875 & 0.000 \\
\hline Sympetrum striolatum* & 0.0846 & 0.1088 & 0.242 & 0.487 & 2.36 & +3.60 \\
\hline Mean & -0.194 & -0.107 & -0.0438 & -4.25 & -1.56 & -0.546 \\
\hline S.E. & 0.0510 & 0.0715 & 0.0801 & 1.01 & 1.54 & 1.96 \\
\hline
\end{tabular}

${ }^{*}=$ species with an egg diapause.

Table 2 - Summary of 1-sample, 2-tailed $t$-test results for samples of $t$-values from Table 1 (see text for details).

\begin{tabular}{|l|l|l|l|}
\hline Flight statistic & Variable & $\boldsymbol{t}$ & $\boldsymbol{p}$ \\
\hline Q1 & Year & -3.81 & 0.001 \\
\hline Median & Year & -1.49 & 0.148 \\
\hline Q3 & Year & -0.55 & 0.590 \\
\hline Q1 & Mean CET & -4.22 & $<0.001$ \\
\hline Median & Mean CET & -1.01 & 0.320 \\
\hline Q3 & Mean CET & -0.28 & 0.783 \\
\hline
\end{tabular}


Table 3 - GLM results for "Q1 vs. year" $T$-sample with the model: "spring or summer species" + "taxonomy" + "egg diapause".

\begin{tabular}{|l|c|c|}
\hline Variable & $\boldsymbol{F}_{\mathbf{1 , 2 3}}$ & $\boldsymbol{p}$ \\
\hline Spring or summer species & 0.30 & 0.588 \\
\hline Taxonomy & 0.62 & 0.439 \\
\hline Egg diapause & 4.32 & 0.049 \\
\hline
\end{tabular}

Table 4 - Results of 1-sample, 2-tailed $t$-tests against test means of zero for samples of $t$-values for species possessing and lacking egg diapause.

\begin{tabular}{|l|l|c|c|c|c|}
\hline Variable & Egg diapause & $\boldsymbol{n}$ & Mean & $\boldsymbol{t}$ & $\boldsymbol{p}$ \\
\hline Q1 vs. date & Absent & 19 & -0.273 & -4.96 & $<0.001$ \\
\hline Q1 vs. mean CET & Absent & 19 & -5.821 & -5.06 & $<0.001$ \\
\hline Q1 vs. date & Present & 8 & -0.006 & -0.08 & 0.940 \\
\hline Q1 vs. mean CET & Present & 8 & -0.518 & -0.38 & 0.714 \\
\hline
\end{tabular}




\section{Figure legends}

Figure 1 - A comparison of changes in Q1 flight dates between those species that possess egg diapause ("present") and those that lack egg diapause ("absent") with respect to time $((A)$ : days per year) and mean CET ((B): days per $1^{\circ} \mathrm{C}$ increase in temperature). 
Figures

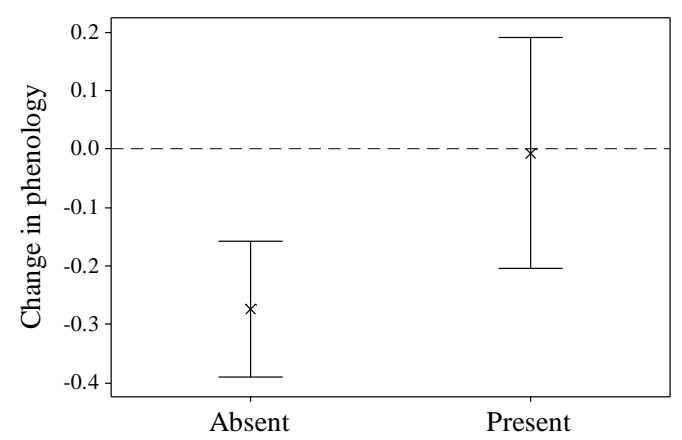

(A)

(B)

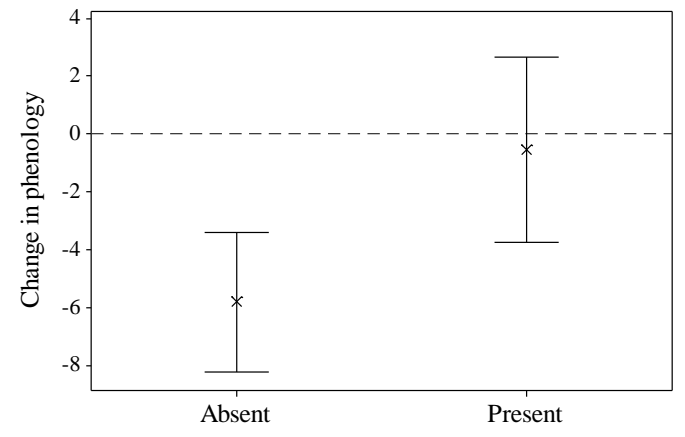

